\title{
20. OPTICAL STUDY OF ORGANIC MATTER FROM SOME SAMPLES OF CRETACEOUS AGE, LEG 47B, HOLE 398D
}

\author{
A. Doerenkamp and P. Robert, Société Nationale Elf-Aquitaine (Production), Boussens 31360, France
}

\section{INTRODUCTION}

This study concerns 25 samples from Cores 56 to 127 (Cenomanian to Barremian), plus 1 sample from Core 39 (probably Danian). All these samples were processed for palynological study and for assessment of organic content; 11 were processed for examination in reflected light (Figure 1).

The following samples were processed: $39-1,51-66 \mathrm{~cm}$; $56-1,20-30 \mathrm{~cm} ; 56-2,120-130 \mathrm{~cm} ; 58-2,74-80 \mathrm{~cm} ; 59-2$, $120-150 \mathrm{~cm} ; 60-1,84-90 \mathrm{~cm} ; 62-1,0-33 \mathrm{~cm} ; 69-2,44-50 \mathrm{~cm}$; $71-2$, 45-50 cm; 72-5, 25-35 cm; 74-3, 83-118 cm; 75-1, $29-62 \mathrm{~cm} ; 78-3,130-135 \mathrm{~cm} ; 81-4,15-20 \mathrm{~cm} ; 86-5,0-38 \mathrm{~cm}$; 91-2, 125-130 cm; 92-6, 115-120 cm; 97-1, 125-130 cm; $101-4,121-131 \mathrm{~cm} ; 103-3,75-80 \mathrm{~cm} ; 111-5,105-110 \mathrm{~cm}$; $112-3,115-120 \mathrm{~cm} ; 119-5,24-44 \mathrm{~cm} ; 120-5,55-60 \mathrm{~cm}$; $125-5,122-150 \mathrm{~cm} ; 126-4,10-43 \mathrm{~cm}$; and $127-5,80-110 \mathrm{~cm}$.

\section{METHODOLOGY}

\section{Study in Reflected Light}

The organic matter was concentrated by physical means only, i.e., froth flotation and gravity, on 50 to 100 grams of rock. The organic residue was embedded in polyester resin and polished for microscope analysis in oil immersion (Zeiss Photomicroscope and Leitz Ortholux; photometry in unpolarized monochromatic light, $546 \mathrm{~nm}$ ).

The reflectance of vitrinite and bitumen was determined by taking, where possible, 30 measurements per sample. Vitrinite (huminite) and bitumen are distinguished on the histograms (Figure 1).

The nature of the liptinic macerals of coals and other organic particles with high levels of hydrogen was determined more accurately by UV or blue-light excitation (fluorescence).

\section{Palynological Study}

The 25 samples were processed in the classical palynological method: $\mathrm{HCl}, \mathrm{HF}, \mathrm{HNO}_{3}$, and gravity separation by bromoform plus alcohol mixture.

\section{RESULTS}

\section{Nature and Origin of the Organic Content}

Throughout the stratigraphic section studied, the organic carbon content is generally low. The exceptions are a few samples (Sections 127-5, 126-4, 119-5 through 120-5, 97-1, and 60-1) in which it exceeds 1 per cent and, principally, Section 56-2 which reaches 7.50 per cent. Sections 39-1 and 56-1 contain only 0.15 and 0.10 per cent organic carbon, respectively; no organic material was recovered after palynological and physical processing. On the whole, the organic content corresponds mostly to a terrestrial, high plant ligneous material. A few samples contain amorphous sapropelic matter, some of which is fluorescent.

On the palynological slides, the ligneous material is clearly composed of wood fragments, generally brown and often opaque, and of coaly particles. Some slides, however, show amorphous material which could be partly of humic origin.

Two samples processed for reflected light study contain humic material. Section 126-4 contains a typical humic coal facies that is humocollinite and telinite with cutinite and sporinite. Section 56-2 contains two kinds of particles: somewhat gelified, frequently stratified, and better polished ligneous fragments, and the nongelified fragments, which show a lower reflectance (Figure 1). The latter, more roughly polished material corresponds partly to the " amorphous matter" observed on the palynological slide. This amorphous matter is not to be confused with typical sapropelic material.

All the samples contain spores and pollen grains, sometimes in great amount (Cores 125, 126, 127). Dinoflagellates of marine origin tend to be more abundant in the middle and late Albian (Figure 1).

The non-humic material is rare, but occurs in some samples. Section 56-2 contains sapropelic material consisting of small unicellular algae and brown-yellow fluorescent groundmass. The qualitative estimation of the fluorescence is 2 on a $5 / 5$ scale corresponding to a fully fluorescent boghead coal. As emphasized previously, this sample is not to be considered a good sapropelic facies although, in palynofacies terms, it is composed almost totally of amorphous matter.

Section 60-1 contains a high percentage of amorphous matter which is a mixture of humic and algal material. Sections 78-3 and 81-4 also contain amorphous matter of possible algal origin; few fragments of alginite and algae are observed in reflected light.

Most of the samples studied by reflected light contain small particles and droplets of bitumen. They are generally embedded in rock fragments or sometimes located in pores. They are sometimes oxidized on their borders.

\section{Thermal Maturation}

Only two histograms of huminite reflectance are reliable, those of Sections 56-2 and 126-4. The first is bimodal, i.e., based on two types of particles which are more or less gelified. The gelified particles may be considered more typical and reliable, thus leading to an estimation of reflectance at 0.40 per cent. The reflectance of Section 126-4 is estimated at 0.47 per cent, which is slightly higher.

The above data are in agreement with the Thermal Alteration Index (TAI) of spores and pollen grains (2.5). The TAI 


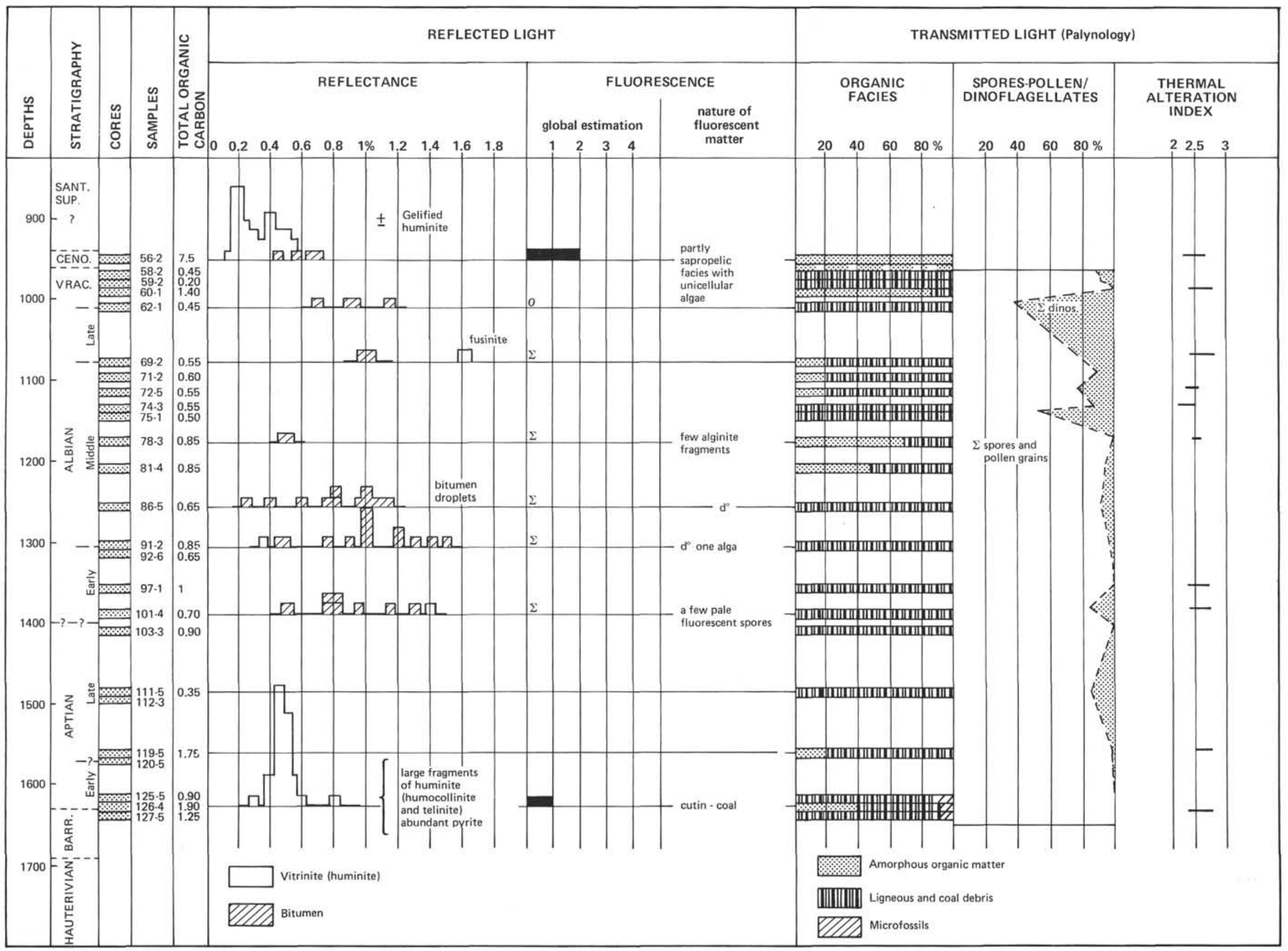


does not show a clear trend between 950 and 1625 meters. The slight differences may be due to the effect of lithology.

The measurement values for bitumen particles show scatter and vary from 0.5 to 1.5 per cent. This indicates that these frequently oxidized elements are probably allochthonous material.

\section{CONCLUSIONS}

1. The organic content of the 25 Cretaceous samples is variable. It is fairly abundant in the early Aptian and, except for Samples 56-2 and 60-1, is less than 1 per cent in the rest of the stratigraphic section.

2. Most of the samples contain typical ligneous material of terrestrial plant origin.
3. Some samples (e.g., Sections 60-1, 78-3, and 81-4), with a high organic content of close to 1 per cent, contain amorphous organic matter together with plant debris. In spite of the presence of sapropelic material, they do not have a high hydrocarbon potential.

4. Section 56-2 is very rich in organic carbon, with 7.5 per cent. It is made up of amorphous material which is not purely of a sapropelic type. Nevertheless, it shows moderate hydrocarbon potential because it is composed partly of sapropelic material, as shown by fluorescence.

5. The actual value of thermal maturation is low; it corresponds to a reflectance close to 0.50 per cent. It must be considered relatively high, however, when compared with mean temperature gradients for such depths. 